its functions are seriously impaired." After this the presence of latent tuberculosis. (Ganghofner, ${ }^{2}$ examination he went home.

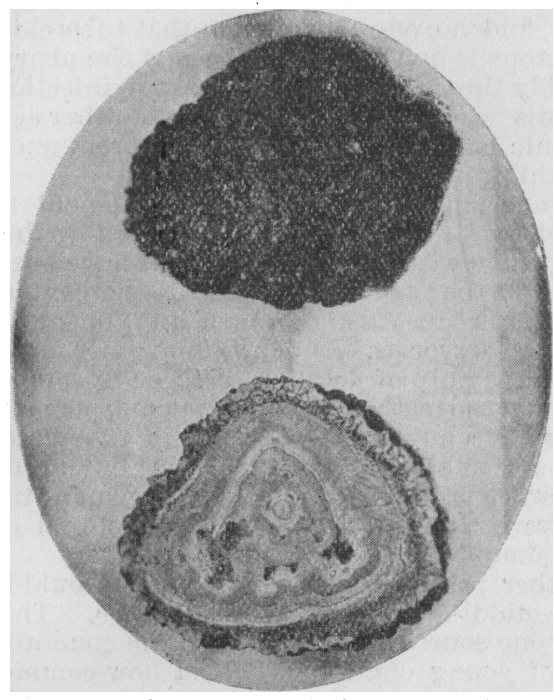

Fig. 2.-Appearance of the stone.

A letter dated May 11th, 1905, was received from the patient, and another from Dr. Owen, saying that his water was right enough and passed without pain, but that he often had pain in his back when walking, so that for days at a time he sometimes could not go out. He had not yet begun work again. One cannot help suspecting stone in the kidney, and hoping for an opportunity of submitting him to $x$-ray photography to try and settle the point; but he is difficult to entice into hospital again, even for so harmless a purpose.

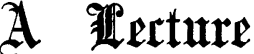

ON

\section{PULMONARY TUBERCULOSIS IN CHILDREN.}

Delivered at the Medical Graduates' College and POLYCLINIC ON APRIL 3RD, 1906.

BY J. EDWARD SQUIRE, C.B., M.D.,

PHYSICIAN TO THE MOUNT VERNON CONSUMPTION HOSPITAL; LECTURER ON MEDICAL ANATOMY AND PHYSICAL DIAGNOSIS TO THE MEDICAL GRADUATES' COLLEGE.

Pulmonary tuberculosis in children is interesting owing to its frequency, its mode of onset, and the indefinite signs by which in many cases it is accompanied.

Frequency.

Tuberculosis is, of all diseases, the most common and the most fatal in infancy and childhood. In the RegistrarGeneral's returns for 1903 the deaths of children from tuberculosis in its various forms are shown as follows:

\begin{tabular}{c|c|c|c}
\hline 0-5 Years. & $5-10$ Years. & $10-15$ Years. & Total. \\
\cline { 2 - 3 } & 2,439 & 2,039 & 16,650 \\
\hline
\end{tabular}

This, however, does not represent the full extent to which tuberculosis affects children, for some, at least, recover, some linger on till they are over 15 , and many children who die of some other complaint (and are therefore not included amongst the tuberculous in the RegistrarGeneral's returns) show evidence of the disease on postmortem examination. The proportion of this latter class is considerable, as is evidenced by the returns of autopsies of the various children's hospitals in Europe and America. Even when we have taken into account all the cases indicated above it would seem that we have not included all the possible cases of tuberculosis in children, for it has been found that in many cases where ordinary pathological examination-macroscopic and microscopic-has afforded no evidence of tuberculosis, inoculation experiments prove
Harbitz. ${ }^{2}$ )

It is, however, to tuberculosis of the lungs that I propose to direct your attention, and the figures I have quoted include tuberculosis of all organs. In infancy tuberculosis, whatever be the seat of the primary infection, tends to become quickly generalized, and tuberculosis in the lung, even if this organ is the primary seat of the disease, is almost always associated with tuberculosis of other organs - a part only of a generalized tuberculosis. When tuberculosis attacks a young child, the lungs are almost always affected sooner or later. This is well shown in the records of autopsies. Of 72 cases of tuberculosis in the first two years of life, $\mathrm{Holt}^{3}$ found the lungs were involved in all; and in 119 autopsies on tuberculous children of various ages, 66 per cent. being 2 years old or less, the same observer found the lungs affected in 99 per cent. In the reports of the Children's Hospital at Pendlebury, Manchester, for 1885 and $1886,{ }^{4}$ out of 54 fatal cases of tuberculosis in children from 9 months to 13 years of age, 52 had the lungs affected, giving a percentage of 96 . With older children the proportion becomes somewhat smaller. In Still's ${ }^{5} 269$ cases of tuberculosis in children under 12 years of age the lungs were affected in 210 , or 78 per cent.

It is said (Holt) that during the first two years of life tuberculosis, with great uniformity, involves first the bronchial lymphatic glands and the lungs; generally it is the lung mischief which kills, though not infrequently it. is meningitis.

Beginning with the third year, tuberculosis of bones, cervical glands, peritoneum, and intestines becomes more frequent, though the lungs are usually involved as well. In these young children the lung mischief is, as a rule, widely diffused and not, as so generally occurs in adults, localized to one portion of the lung.

After the sixth or seventh year-the period of the second dentition-the pathological processes tend to resemble those of adults. Generally speaking, the younger the child the more diffuse is the tuberculous mischief in the lungs. In infants and young children the physical signs of tuberculosis in the lungs resemble those produced by bronchopneumonia, and a differential diagnosis has to be arrived at by the prolonged course of the illness and the persistence of the physical signs or by the signs of tuberculosis in other parts.

Though I may occasionally refer again to pulmonary tuberculosis in infants, I think it will be most useful to the majority of those in practice to confine my remarks chiefly to the cases occurring in older children; this is also the more desirable, since my personal experience of pulmonary tuberculosis in children over 5 years of age is much larger than that of the disease in infants.

It will be seen from the following table which $I$ have drawn up from the Registrar-General's returns that the deaths from phthisis fall after the fifth year until the tenth year and then again rise. This increase shows itself earlier in the case of females, and swells the number of deaths in girls from 10 to 15 years of age. In males the increase comes later (when they get out to work) and is not marked until childhood is past.

Total Deaths (England and Wales) from Phthisis and Pulmonary Tuberculosis, 66th Report of the RegistrarGeneral (1903).

\begin{tabular}{cc|c|c|c|c|c}
\hline & $\begin{array}{c}\text { Under } \\
\text { 1 Year. }\end{array}$ & $\begin{array}{c}\text { 1 to 5 } \\
\text { Years. }\end{array}$ & $\begin{array}{c}\text { 5 to 10 } \\
\text { Years. }\end{array}$ & $\begin{array}{c}10 \text { to 15 } \\
\text { Years. }\end{array}$ & $\begin{array}{c}\text { Total } \\
\text { under 15 } \\
\text { Years. }\end{array}$ \\
\hline Males & $\ldots$ & 213 & 494 & 279 & 290 & 1,276 \\
Females & $\ldots$ & 201 & 409 & 343 & 702 & 1,655 \\
\hline Total & $\ldots$ & 414 & 903 & 622 & 992 & 2,931 \\
\hline
\end{tabular}

Pulmonary tuberculosis in children shows certain clinical points of difference from consumption in adults in the path of entry of the infective bacillus into the lung; in the mode of development of the disease; and in the signs by which its presence is manifested.

Path of Infection.

The source and path of entry of the infection of tuberculosis in children demands consideration, since on a 
proper understanding of this depends, to a large extent' our precautions to prevent infection; and by a knowledge of the usual seat of the initial lesions we may be the better enabled to recognize the disease in an early stage. Though in infants infected milk may be a source of infection, in older children it may be confidently asserted that the general cause is the inhalation of air contaminated with tubercle bacilli of human origin.

The path of entry into the lung is more difficult to determine. Most authorities agree in considering infection of the bronchial lymphatic glands as a usual halfway house, as it were, between the passage of the tubercle bacilli through the mucous membrane of the respiratory passages and their invasion of the lung substance.

That in some cases the bronchial glands become affected first, the disease spreading from the gland to the root of the lung, is undoubtedly true; but there seems good reason to believe that the reverse order of infection may be much more frequent than seems to be the generally accepted impression. No doubt the lymphatic glands at the root of the lung are generally affected with the lungs in children-early youth is the period of greatest lymphatic activity, and the glands rarely escape disease when a child becomes infected with tuberculosis. It seems from post-mortem records that in a very large proportion of cases the condition of the tuberculous process in the glands appears to be more advanced than that in the lungs. It does not, however, follow that the disease commenced earlier in the glands than in the lung, though it may have advanced more rapidly in the former. When the disease spreads from a tuberculous bronchial gland to the lung we should expect to find evidence of tuberculosis near the root of the lung. This is the case in many instances, and clinically we meet with cases where the physical signs of tuberculosis are found most evident in the mammary region and in the right lung are almost confined to the middle lobe, suggesting extension from a bronchial gland. In a large proportion of cases of pulmonary tuberculosis in children, and particularly in older children, the lung mischief is located in the apex of the lung, at a distance from the root, and it is more reasonable to suppose the gland to have become infected through the lymph stream from the lung than to infer that the mischief has spread from the gland to the lung. Dr. Paul Matthews ${ }^{6}$ gives a series of 25 cases of tuberculosis in children, in 23 cases of which the lungs were affected, and in 19 of these the bronchial glands were also involved. I have attempted to classify these according as the lungs or the glands appear to have been first affected, with the following result :

\begin{tabular}{|c|c|c|c|c|}
\hline & $\begin{array}{c}\text { Lung affected } \\
\text { first } \\
\text { (most advanced) }\end{array}$ & $\begin{array}{l}\text { Bronchial Glands } \\
\text { first affected } \\
\text { (most advanced). }\end{array}$ & $\begin{array}{l}\text { Lungs and } \\
\text { Glands } \\
\text { equally in } \\
\text { volved. }\end{array}$ & Totals. \\
\hline Under 3 years & $\underset{4}{\text { Cases. }}$ & $\underset{5}{\text { Cases. }}$ & $\underset{6}{\text { Cases. }}$ & $\underset{15}{\text { Cases. }}$ \\
\hline $\begin{array}{l}\text { of age } 3 \text { years ... } \\
\text { Over }\end{array}$ & 5 & 0 & 3 & 8 \\
\hline Total ... & 9 & 5 & 9 & 23 \\
\hline
\end{tabular}

A series of careful observations recently published (Dr. Russell) tend to confirm this view. Dr. Russell ${ }^{7}$ made a series of inoculation experiments on guinea-pigs, and traced the course of extension of the infection. He found that in several instances the lungs became affected whilst the bronchial glands remained free; in other animals, in whom the glands were affected whilst the lungs seemed to be clear, careful examination demonstrated that there was tuberculosis present in the lungs. He points out that the great difference in size between the lungs and the gland makes it easy to detect changes in the glands and to overlook tnberculous foci in the larger organs; also that the tuberculous process in the gland, when once commenced, advances more rapidly than do the changes in the lung foci. Thus disease commencing later in the gland may soon overtake that in the lung, and, being then more advanced, suggests that it is of longer duration. Whether the glands or the lungs become affected first, we have still to consider where the bacilli get through the mucous membranes of the air passages. The observations of Walsham ${ }^{8}$ and others point to the tonsils and the adenoid tissue at the back of the naso-pharynx as one point of entry of bacilli into the lymph channels. I succeeded fifteen years ago in infecting the cervical lymphatic glands in rabbits through the tonsils and pharynx, and no one now doubts that tubercle bacilli get. into the tonsils and adenoid tissues of the pharynx.

Probably there is much more risk of infection through the tonsils when these are inflamed, either acutely or in the chronic enlargement which is far from uncommon in weakly children

The importance of the post-nasal adenoid tissue as a path of entry for tubercle bacilli is shown by the comparative frequency with which these bacilli have been found in adenoid growths; as much as 12 to 15 per cent. (Morgan ${ }^{9}$ ). Decayed teeth must also be taken into consideration. An American observer (G.W.Cook ${ }^{10}$ ) frequently found tubercle bacilli in the pulp of decayed teeth or in scrapings taken from around the teeth, especially in young persons. How far this may have any causal relation to tuberculosis in the lungs I am unable to say, but I am convinced that both in relation to prophylaxis and to treatment of tuberculosis in children, as in adults, attention to oral and dental hygiene should not be overlooked.

One other possible source of danger should be notednamely, middle-ear and mastoid disease. This is recognized as one source of infection in the generalized tuberculosis of young children. Seeing how common middleear disease is amongst the children of the poor in London, this question is worthy of consideration.

From recent inquiries and observation in some of the elementary schools in London I have found that the proportion of children attending these schools in whom thereis discharge from the ears varies in different schools from 0.4 per cent. to 6 per cent., according as the children are living in very poor or in better class districts. Taking over 5,000 children on the rolls of schools which I have visited in different localities, I find the proportion affected with ear discharges to be 2 per cent., which agrees very closely with the proportion found in the whole of theCounty Council schools in London by Dr. Kerr, the Medical Officer of the Education Department of the Council.

It must not be assumed that all, or nearly all, of thesecases are suffering from tuberculous disease of the ear, but if not more than 2 per cent. of these ear discharges: are due to tuberculosis it is not altogether a negligible quantity. Dr. Price Jones, ${ }^{11}$ in discussing the causation of tuberculosis in children, draws attention to middle-eardisease as a possible cause of pulmonary tuberculosis, and records cases in illustration. I have recently had a caseunder my observation in which, in an adult, middle-ear disease seemed to have been the starting point of tuberculous infection of the lung.

The predisposing causes of consumption are as important with regard to children as in the case of adults. Children are peculiarly susceptible to unhygienie conditions, and the influence on the causation of tuberculosis in children of overcrowding, dirt and neglect, insufficient. or improper food, is very potent. Debilitating illnesses, such as measles, influenza, whooping-cough, pneumonia, etc., also have an influence which must not be overlooked. How great is the predisposing influence of overcrowding: and its attendant evils on the prevalence of pulmonary phthisis in children, and especially in young children, is seen from a table in the Registrar-General's Report (1903): taking an average of five years the phthisis mortality for children under 5 years of age for the whole of England and Wales is 355 per million living. In the urban counties the corresponding rate is 401 , whilst in rural counties it is only 268.

Mortality from Phthisis per Million Living. (From the 66th Annual Report of the Registrar-General, 1903.)

\begin{tabular}{|c|c|c|c|c|c|c|}
\hline \multicolumn{4}{|c|}{ Loth Sexes. } & $0-5$. & 5-15. & Total. \\
\hline $\begin{array}{l}\text { England and Wales : } \\
\text { Average } 5 \text { year's } \\
1903 \ldots\end{array}$ & $\ldots$ & $\ldots$ & $\begin{array}{l}\ldots \\
\ldots\end{array}$ & $\begin{array}{l}355 \\
345\end{array}$ & $\begin{array}{l}237 \\
229\end{array}$ & $\begin{array}{l}592 \\
574\end{array}$ \\
\hline $\begin{array}{l}\text { Urban Counties : } \\
\text { Average } 5 \text { year's } \\
1903 \ldots \quad \ldots \quad \ldots\end{array}$ & $\ldots$ & $\ldots$ & $\begin{array}{l}\ldots \\
\cdots\end{array}$ & $\begin{array}{l}401 \\
419\end{array}$ & $\begin{array}{l}246 \\
231\end{array}$ & $\begin{array}{l}647 \\
650\end{array}$ \\
\hline $\begin{array}{l}\text { Rural Counties : } \\
\text { Average } 5 \text { years } \\
1903 \ldots \quad \ldots\end{array}$ & $\ldots$ & $\ldots$ & $\begin{array}{l}\ldots \\
\ldots\end{array}$ & $\begin{array}{l}268 \\
252\end{array}$ & $\begin{array}{l}235 \\
233\end{array}$ & $\begin{array}{l}503 \\
485\end{array}$ \\
\hline
\end{tabular}


Symptoms and Clinical Types of Pulmonary Tuberculosis in Children.

To the practitioner, however, interesting though the study of causes of disease may be, it is the detection and treatment of disease when it has attacked the individual which is of practical importance. I pass, therefore, to a consideration of the symptoms and clinical types of pulmonary tuberculosis in children.

Tuberculosis affects the lungs of children in different ways, giving rise to various clinical types which, though distinct enough in well-marked cases, tend to run into one another. The simplest division of clinical varieties appears to be into $(a)$ infantile and $(b)$ adult types. The infantile group may be subdivided into miliary and bronchopneumonic; the adult into apical and basic cases.

\section{Infantile Type.}

Miliary Tuberculosis of the Lung.-This is essentially the type associated with generalized tuberculosis in young children. Scattered through both lungs are areas thickly dotted with miliary tubercles, or the whole of both lungs may have these small tubercles distributed throughout their substance. With these grey granulations some parts of the lungs may appear healthy; other portions give the appearance of bronchopneumonia. The pleura generally shows tabercles. The general appearance of the lung is similar to that seen in ordinary bronchopneumonia, but with the grey granulations dotted about in it. The physical signs in the chest will be those of bronchopneumonia. Diminished resonance and resistance on percussion will be found in patches or over the whole chest. Moist râles and crepitations of various sizes will be heard everywhere over the affected parts. Breathing may be quickened. Cough is frequent, sometimes paroxysmal when enlarged bronchial glands press on the pneumogastric nerve. When expectoration is present the sputum is generally frothy, as in bronchitis. Fever is almost always present ; emaciation generally marked; weakness extreme and cerebral symptoms not uncommon. Evidence of tuberculosis in other organs may often be obtained, and a fatal termination is almost invariable. Occasionally the symptoms suggest typhoid fever, and mistakes in diagnosis are not unknown. This miliary tuberculosis, though not uncommon in infants, becomes less seen as age advances. It is not frequently met with after 5 years of age.

The bronchopneumonic type, or tuberculous bronchopneumonia, is also most frequent in infants and young children. The course is more prolonged than in miliary tuberculosis. There is, as a rule, considerable dense consolidation of portions of the lung, more frequently at the apex than at the base; the pleura is generally thickened over the affected area, and adhesions form. Softening (caseation) takes place in the consolidated lung, and cavities are formed. The physical signs are dullness on percussion, tubular or bronchial breathing, numerous crepitations -at first fine, and then, as softening commences, larger and more liquid. The presence of cavities may be indicated by the altered character of the breath sounds, but cavities are less easily recognized in children than in the adult. The general symptoms are less marked than in the acute miliary variety, the illness being less acute. Cough may be almost absent at first, but is generally frequent when softening occurs, and if there is expectoration the phlegm is thick and yellow or greenish.

As an example of the bronchopneumonic type of pulmonary tuberculosis I select a case which I saw in consultation at Watford, because the microscopic examination of the sputum showed the presence of tubercle bacilli, leaving no doubt as to the diagnosis.

CASE I.-A little girl, $5 \frac{1}{2}$ years of age, had been ailing somewhat for about six weeks, but with no very definite symptoms. About a fortnight before I saw her, just before she was going away from home on a visit, her temperature one evening was found to be $102^{\circ} \mathrm{F}$. She returned home three days before was called in, looking very ill and evidently much worse than when she left home. The temperature was raised every evening to $100^{\circ}$ and over. There was no history of tuberculosis in the ramily. When I examined her, about 4 o'clock p.m., the temperature was $103^{\circ} \mathrm{F}$. There was dullness on percussion ove the left base, with numerous moist râles. Crepitations wer scattered through the upper lobe of this lung, and there were also some large moist crepitations at the apex of the right lung. The physical signs at the base of the left lung were undistinguishable from those of an acute bronchopneumonia. The history of the illness, however, indicated the nature of the disease, which, as I have said, was confirmed by the examination of the sputa.

\section{Aduit Type.}

In children over 6 years of age tuberculosis in the lungs often takes a form in all respects similar to that characterizing consumption in the adult. This is the "chronic tuberculous phthisis" of most authors. The signs, symptoms, and course need not be described, since they are only too commonly seen in the adult consumptive.

A few points of interest may, however, be noted : First, as to the part of the lung primarily attacked. The base may be first involved more frequently than in adults, and when the disease spreads to the lung from a caseous bronchial gland the physical signs of the mischicf will be found over the situation of the root of the lung-about the mammary region of the chest. Still, as in adults there is a marked preponderance of apex cases.

Another point is that the bronchial glands are frequently involved in the tuberculous process; so signs and symptoms specially due to the enlargement of these glands may be noted. These signs and symptoms are chiefly due to pressure upon the neighbouring blood vessels, nerves, or air tubes. Thus pressure upon the superior vena cava or the innominate vein will cause fullness of the superficial veins of the face, neck, chest, or shoulder, or one or both sides, as the case may be. If the pressure be considerable, we may get cyanosis and puffiness of the face. Pressure on the trachea may give rise to some cough and difficulty in breathing, constant or occasional. Some so-called "asthmatic attacks" in children are attacks of dyspnoea due to the pressure of enlarged bronchial glands on the air tube. Similar paroxysmal attacks of dyspnoea and paroxysmal cough, resembling that of whooping-cough, may be caused by the pressure of such glands on the pneumogastric nerve. I have seen a case in which paralysis of the right vocal cord was associated with signs of enlargement of bronchial glands, and was apparently due to pressure upon the right recurrent laryngeal nerve. The enlargement of the gland became less under treatment, but, although other pressure symptoms and signs disappeared, the paralysis of the vocal cord remained; apparently some inflammatory infiltration around the gland had involved the nerve and compressed it.

Enlarged bronchial glands rarely give rise to distinctive physical signs by which their presence may be definitely inferred. Pressure on the bronchus may give rise to high-pitched tubular breath sounds over the affected branch of the air tube, or may so interfere with the entrance of air to the lung as to cause the breath sounds on the affected side to be much weaker than those on the opposite side of the chest. Pressure on the root of the lung may, by obstructing the return of blood through the pulmonary veins, cause mechanical congestion of the lung, indicated by diminished percussion resonance and crepitations at the base. So, also, murmurs may be caused in arteries or veins from pressure on them of enlarged glands.

The symptoms vary greatly in pulmonary tuberculosis in children. Cough may be entirely absent, or so slight as to be unnoticed. When present, the character of the cough varies greatly in different cases. Sometimes we have the almost constant, irritating, dry cough, preventing sleep and wearing the child out by its persistence; in other cases the paroxysms of violent cough suggest whooping-cough; or again we may have the liquid cough of bronchitis. Children under 6 or 7 years of age rarely expectorate, however much phlegm may be brought up into the mouth by the cough. If very plentiful, or when muco-purulent the phlegm may cause vomiting, but as a rule it is swallowed. This, of course, prevents the possibility of assisting diagnosis by the microscopical examination of the sputum. It will, perhaps, be possible sometimes to collect a little of the phlegm which may remain hanging about the throat or fauces after a cough or to select a specimen of sputum from the vomited matter. A bougie, probang, or tube passed down the oesophagus may withdraw sufficient mucus adhering to it to allow of microscopical examination. Though older children do expectorate, they will frequently swallow the phlegm if they are not trained to expel it. It is, however in my experience very much less common for pulmonary 
tuberculosis in children to be accompanied with cough with expectoration than is the case with the same disease in adults.

It is in consequence of the habit of swallowing the sputum that children so frequently get secondary infection of the intestine with consequent diarrhoea. Secondary infection of the tonsils may also result from the phlegm which is coughed up into the mouth. Infection of the lârynx is less common in children than in adults.

Haemoptysis is not common in children. In my cases there is a history of haemorrhage in 10 per cent., whicb seems to be above the average, since Herz (quoted by Holt) found this accident only eight times in 247 cases of clinical tuberculosis in children.

In the Pendlebury Hospital haemoptysis was the cause of death in 4 cases out of 131 autopsies on tuberculous children. Haemoptysis rarely, if ever, occurs in children under 3 years of age.

Shortness of breath (dyspnoea)also seems less prominent as a symptom of phthisis in children than in adults.

Fever may be present at some time in the majority of cases. The fact that fever is present is important; the character of the fever is of comparatively little assistance in diagnosis.

In acute cases it may be almost continuous, and frequently high. A diurnal range extending over three or four degrees or more may be met with. In other equally acute cases, the temperature may rarely rise above $100^{\circ} \mathrm{F}$. In the more chronic cases fever may be practically absent. The temperature varies between $98^{\circ}$ and $99^{\circ}$, with an occasional rise to $100^{\circ}$ or over at rare intervals; unless the temperature is taken regularly over a long period these rises may be altogether overlooked. The breathing is generally slightly quickened; the pulse rate also, is generally quicker than in health.

The general symptoms also vary greatly in different cases. Progressive emaciation and weakness may be the chief initial indications of ill-health; on the other hand, children with unmistakable physical signs of tuberculosis in the lungs may remain plump and robust in appearance, with good colour, lively and cheerful spirits, and no outward signs of impaired health.

The physical signs in the chest are also very variable. In cases where the disease has affected any considerable portion of the lungs there will, on examining the chest, be little difficulty in detecting evidence of changes in the lung. The difficulty consists in deciding whether the changes evidenced by the physical signs are due to tuberculosis, or to some other morbid condition. In infants and young children the signs of tuberculosis in the lung so closely resemble those of bronchopneumonia that it is often impossible to distinguish between the two diseases ; in fact, the signs are those of a bronchopneumonia set up by the tubercle bacillus. When these signs are limited to the apex of the lung, as it may be in a fair proportion of the cases, the probability of a tuberculous origin is strong. The history of the illness wil often give some indication of its nature, the gradual onset of tuberculosis being in marked contrast to the more sudden commencement of simple bronchopneumonia.

In older children the physical signs are more distinctive. There is some diminution of the respiratory movements at one apex, with deficient percussion resonance; the breath sounds over the affected area are weak and harsh, jerky, bronchitic, tubular, or even cavernous, according to the stage which the disease has reached in the part examined.

The expiratory portion of the breath sound is almost always prolonged, and may be louder than the inspiratory. In early cases no râles or other adventitious sounds may be heard; in later stages crepitations of various sizes, clicking, or bubbling râles may be heard. It is not uncommon in children to hear the marked tubular or cavernous breathing, which in the adult would indicate excavation, when consolidation and not cavitation is the actual condition present. Whispering pectoriloquy may also be obtained under similar circumstances, and even a cracked-pot percussion note in a child does not necessarily indicate a cavity in the lung.

In these older children the mischief commences in the apex of the lung much more frequently than in the base. Even in quite young children the number of apex cases is in excess of those commencing at the base; as age advances the preponderance of apex cases becomes greater.
I have looked through a number of cases which have been under my observation in hospital and private practice during the past year or so, and I find that where it has been possible to form an opinion as to the seat of the initial mischief in the lung, this has been in the upper lobe in exactly five-sevenths of the cases. The actual figures are as follows:

Out of 105 cases in children from 3 to 15 years no opinion could be formed as to the seat of the initial lesion in 49 . In the remaining 56 cases the disease commenced at the apex in 40 , and at the base in only 16. The proportion of apical to basic cases appears to depend to some extent upon the ages of the children examined. Holt out of 127 cases in younger children found the numbers to be : Upper lobe, 69; middle lobe, 23; lower lobe, 35. This is very nearly the same proportion as in my cases if the middle lobe is included with the upper lobes.

As examples of the adult type I will take a case in an early stage of the disease; one which had advanced to cavitation, but remained subacute; and one in which the

advanced and the symptoms extremely acute.

CASE II.-A schoolboy, aged 11 years, was kept away from CASE II.-A schoolboy, aged 11 years, was kept away from
school with cough, but with no expectoration. His pulse-rate school with cough, but with no expectoration. His pulse-rate and temperature were taken regularly for a week or two, and were rather significant of tuberculosis. When I examined him ness in the breath sounds above the left clavicle, a few fine crepitations in the region of the cardiac apex and some prolongation of the expiratory portion of the breath sound above the right clavicle.

CASE III.-E. V., aged 11 years, gave a history of cough for the past six years. On examination there was flattening below the past six years. Ond dullness on percussion down to the third right clavicle, and to the inferior angle of the scapula on this space in front and to the inferior angle of the scapula on this side. Above and below the inner end of the right clavicle and in the supraspinuus fossa behind cavernous breathing with whispering pcctoriloquy were heard; below this the breathing side. On the left side percussion resonance was diminished down to the fourth rib, the breathing over this area was weak, and the expiratory sound prolonged. Moist crepitations were scattered through this part of the lung. Examined by the scattered broug were seen to be sprinkled with mottled $x$ rays, both lungs were seen the right side, but rather more shadows, more extensive on the right side, but rath more dense on the left. The right apex was occupied by a shadow with a definite margin best seen from behind. The child's temperature ranged from $96.4^{\circ}$ to $99^{\circ}$. The pulse-rate varied between 80 and 112 per minute. The weight was $3 \mathrm{st} .13 \mathrm{lb}$. CASE IV.-Ada H., aged 13, whose father, an uncle, and two aunts on the father's side had died of phthisis, had had a cough for some time and an attack of haemoptysis twelve months before admission to hospital. She had not ret menmonth ber of pain over the apex struated. On admission sbe complained of pain over the apex of the left lung. Her temperathre was 10 p., pulse 130 per minute, respirations 30 . On examination the right side was flattened at the apex; the movements were poor ; percussion note dull to the fourth space in front and to the fifth spine behind. Breathing over this area tubular, with fine crackling râles On the left the apex was flat, expansion poor; dull on percussion to the fourth rib in front and to the fifth spine behind. Tubular breathing all over the upper part of the chest, with loud bubbling râles. Some amphoric breathing, with whispering pectoriloguy (cavity) at the apex. At the wase whis side were heard some small, fine crepitant râles. base on this side wirteen weeks later the chest was nearly dry; On discharge thirteen weeks later the chest was neares ; there a few râles were occasionally to be heard over the apices; there was no cough ; appetite good. The temperature for a month
previously had kept generally between $98.4^{\circ}$ and $99^{\circ}$, rising about once in a week to $100^{\circ}$, and about as frequently falling to $98^{\circ}$. She had gained 1 st. $4 \mathrm{lb}$. in weight. She reported herself some time later as keeping well.

In a not inconsiderable proportion of cases where tuberculosis of the lungs is suspected the physical signs in the chest are very indefinite, as is seen in Case II. There may be cough, wasting, and perhaps irregular temperature, and the only signs to be elicited on examination of the chest may be some increased resistance on percussion, with a less resonant note than might be expected from a child's chest, not necessarily localized to any one part of one lung, but general over the whole of one or both sides. On auscultation the breath sounds may be weak, and a few fine crepitations may be heard at the margins of the lung, down the edge of the sternum or over the cardiac area. These crepitations are probably due to emphysema, and might, of course, be due to compensation for partially consolidated lung in the neighbourhood. Such crepitations, in the absence of other signs, are of little significance. I have within the past fortnight had the opportunity of examining a number of healthy children, and out of 268 children, all about 10 to 
11 years of age, I have been able to detect such crepitations in 81 , or - just over 30 per cent. In this connexion it is well to bear in mind that children-especially the younger ones-often flinch a little when the stethoscope touches the chest, and the slight tremor causes the skin to rub against the instrument, and thus gives rise to a friction sound almost indistinguishable from crepitant râles. In strumous children the skin is often dry and rough, and these pseudo-crepitations are the more easily produced.

I have not infrequently been asked to confirm a diagnosis of pulmonary tuberculosis in children when I could tind no evidences of pulmonary disease on examination of the chest. It is, however, well to give a guarded opinion in these cases. Tuberculosis of other organs-bronchial glands, for example-may be present and cause the symptoms which have suggested the diagnosis of phthisis. If that be the case, the lungs will probably become affected sooner or later; and, in any case, the line of treatment will not be affected by the presence or absence of tubercle in the lung. Proper treatment commenced in good time may prevent extension to the lung, or may cure the disease if it has already attacked these organs; delay until definite physical signs present themselves may materially diminish the chances of recovery.

There are certain aids to diagnosis which may in some cases be of use. The $x$ rays may possibly disclose some consolidation in the lung which gave no sufficient evidence of its presence on physical examination. Injections of tuberculin might give clear indications of the presence of tuberculosis, though not of its seat. I have on other occasions given my reasons for having discontinued the use of tuberculin and for considering its use for diagnostic purposes to be risky.

I have not sufficient experience of taking the opsonic index to express any opinion as to its value in assisting diagnosis in doubtful cases in children.

The difficulties of diagnosis are not confined to those cases in which the symptoms and physical signs are few in number and indefinite in character. Pleural effusion may be mistaken for tuberculous infiltration of the base of the lung, and even when consolidation of the lung is undoubtedly present it may be difficult to determine its cause-whether due to the action of the tubercle bacillus or of some other morbific micro-organism, such as the pneumococcus or the influenza bacillus. Pneumonia affecting the apex of the lung may sometimes be only distinguished from tuberculosis by a microscopical examination of the sputum.

In this connexion I may briefly refer to a case recently under my care in hospital :

CASE v.-A girl, aged 14 years, was admitted as an emergency case supposed to be suffering from acute tuberculosis of the lung. She gave a history of three weeks' illness. On admission she was obviously acutely ill, with hectic appearance; temperature $103.4^{\circ} \mathrm{F}$., pulse 128, respirations 32 . There was deficient movement of the right chest, dullness on percussion all over this side, with bronchial breathing and fine moist crepitations. In the left lung there were scattered sibilant rhonchi, with some fine rales at the base behind. I expressed the opinion that the case was one of pneumococcic rather than of tuberculous infection, and this view was subsequently confirmed by the presence of pneumoccocci in the sputum which was free from tubercle bacilli. The girl remained acutely ill for a fortnight, and then she developed a swelling of the right knee, suggestive of tuberculosis, which subsided under treatment after about ten days. The general symptoms and the temperature had begun to improve a few days previously, and her recovery was ultimately complete. She remained under observation for about six months, and at no time were tubercle bacilli found in the sputum.

Prognosis.

The large mortality from pulmonary tuberculosis in children shows that the prognosis must always be a guarded one. The proportion of cases in which healed tuberculosis is found in children who have died from other complaints is evidence that recovery from tuberculosis is not infrequent even in infancy.

To a certain extent we may take it as a rule that the younger the child the more grave is the outlook. We have to bear in mind, however, the greatly increased mortality, in girls especially, after the age of 10 years, and I think we may take it as certain that a large amount of this 4 increased mortality occurs in girls at about the age of puberty. The age of puberty is variable, but is generally in this country within the limits of 12 and 15 years of age.

I have repeatedly pointed out that in girls who become phthisical within these ages the prognosis will be much influenced according as menstruation has or has not already commenced. I have found that tuberculous girls at about the age of puberty in whom menstruation has not commenced have a much better chance of recovery than those who have already menstruated (see Case rv). As I have expressed it, it appears as though a reserve of energy stored up for the completion of sexual development may be diverted from its purpose and utilized in combating the tuberculosis. Puberty in these cases is delayed until the disease has become arrested.

A few words in conclusion as to treatment.

The most important requirement is to put the child under proper hygienic conditions. Life in the open air, good and sufficient food, cleanliness, and a proper amount of rest and sleep, are the essentials. As a rule I consider that children are much better not kept in bed, unless the fever is high and the weakness extreme.

There is a question of much importance with regard to children over 6 or 7 years of age, namely that of education. Ought they to attend school, or have lessons of any kind? I believe they are all the better for having lessons, excepting in acute cases. Without some occupation they tend to become fretful, dissatisfied, and tiresome. If not overpressed, and especially if the lessons can be taken out-of-doors, they will benefit physically, mentally, and morally by carrying on their education whilst under treatment. We must bear in mind that the cure of tuberculosis in children, as in adults, is not a matter of days, or even of a few weeks.

Treatment-in the sense of hygienic management under medical supervision-may be required for months or even for years, and in education we cannot afford to waste the most valuable years of life.

For the poorer children seaside schools-such as the City of Paris has established on the coast for its tuberculous children - and forest (or open-air) schools--such as have been instituted in Berlin--have a great value, both prophylactive and curative. Residential schools on the East Coast for tuberculous children, and open-air lessons in the school playground, or even in the London parks or in Epping Forest, are worth consideration.

Economically, it is more advantageous and less costly to keep the children free from tuberculosis and to treat those who become infected than to attempt to cure the consumptive adult.

\section{REFERENCES.}

1 Ganghofner, International Congress on Tuberculosis, Paris, 1505,

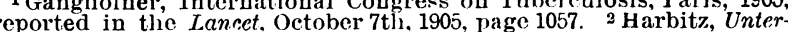
suchungen über die Iräufigkeit, Lokalisation, und Aufbreitungs wege der suchngen uber die Traufighelt, Lok hallon, Tuberculose. 3 Holt, The Diseases of Infancy and Childhood, second treated at the General Hospital for Sick Children. Pendlebury, Manchester. 5 Still, Observations on the Morbid Anatomy of Tuberculosj. in Childhood, BRITISH MEDICAL JOURNAL, August 19th, 1899. "6 Matthews, On theEtiology of Tuberculosis in In fancy and Childhood, Britizh Journal of Children's Iiseases, March. 1906. 7 Dissertation on the Relative Time of Infection of the Lungs and Bronchial Glands in Guinea-pigs: noculated with Tubercular Material, by II. W. Kussell, 1905. 8 Wa] sliam, Channels of Infection in Tuberculosis. Weber-Parkes essay, 1904.

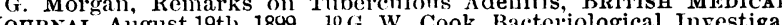
tion of 220 Moutls with Special Reference to Tuberculous Infection. tiontal 220 Mouths with Special Reierence to Truberculous Infection, tion of Tuberculosis in Childreu, Practitioncr vol. lxxi, 19:3.

\section{A CASE OF ACTINOMYCOSIS OF THE} ABDOMINAL WALL

PRODUCED BY AN INFECTED FOREIGN BODY WHICH HAD ESCAPED FROM THE IN'TESTINE.

By ARCHIBALD CUFF, B.A., M.B., B.C., F.R.C.S., SURGEON TO THE ROYAL INFIRMARY, SHEFFIELD.

THE history of the following case is of interest from the way in which the probable mode of infection was demonstrated.

\section{History.}

J. J., a carter, a strong, healthy-looking man, aged 46, was admitted into hospital on April 11th, 1905. complaining of a "lump in the side," which he bad noticed for six months.

On exposing the abdomen a distinctly localized prominence On exposing the abdomen a distinctly localized prominence could be seen, on the right side, touching intercally the semi-
lunar line and extending outwards beyond and above the lunar line and extending outwards beyond and above the 